\title{
تجليات الفلسفة الوجودية في اللسرح العربي \\ (دراسة مقارنة لنماذج مختارة من مسرحيات سارتر وكنفاني)
}

The Manifestations of Existential Philosophy in the Arab theater (A comparative study Between Sartre and Kanafani's selected plays)

$$
\text { د. أحمد مجدي فرج محمود }
$$

مدرس مساعد بقسم الدراما والنقد المسرحي، كلية الآداب، جامعة عين شمس، جمهورية مصر العربية

Email: ahmed.magdy@art.asu.edu.eg

يتتاول البحث بالتحليل الأعمال المسرحية للكاتب الفلسطيني غسان كنفاني التي ساهمت في اعادة انتاج تيار المسرح الوجودي، في ثوب قضايا و اقعنا العربي في الستينيات. وفيه نوضح أهمية مسرحيات كنفاني مثل "القبعة والنبي"، و"الباب" في معالجة قضايا العالم العربي في إطار يجمع بين الفلسفة الوجودية والفانتازيا والسياسة وفي بعض الأحيان الأساطير القديمة، وهو ما سيوضحه الباحث من خلال الدر اسة المقارنة و التناصية بين مسرحيات كنفاني، ومسرحيات مختارة لجان بول سارنر الوجودية في أوروبا مثل جلسة سرية، و الذباب.

يقسم الباحث الدراسة إلى ثلاثة محاور؛ المحور الأول بعد مدخلا للفلسفة الوجودية بين المسرح الأوروبي والمسرح العربي. و المحور الثاني يقارن من خلاله الباحث بين مسرحية جلسة سرية لسارنر ومسرحية القبعة والنبي لغسان كنفاني متناو لا حوار الأنا والآخر في الفلسفة الوجودية بين سارنز وكنفاني. أما المحور الثالث و الأخير فيتناول فيه الباحث كيفية تطويع سارنر وكنفاني للأساطير القديمة سواء إغريقية أو عربية لخدمة افكار هما الوجودية. وتنتهي الدراسة بالنتائج، ثم قائمة بالمصادر و المراجع.

الكلمات المفتاحية: الوجودية، غسان كنفاني، جان بول سارتر ، البير كامو. 


\section{The Manifestations of Existential Philosophy in the Arab theater (A comparative study Between Sartre and Kanafani's selected plays)}

\section{Abstract:}

The research analyzes the theatrical works of the Palestinian writer Ghassan Kanafani, which contributed to the re-production of the existential theater, in the frame of the issues of our Arab reality in the sixties. The research underlines the critical role that Kanafani's texts, such as "The Hat and the Prophet" and "The Door," play in addressing the issues of the Arab world in a framework that combines existential philosophy, fantasy, politics and sometimes ancient myths. The researcher aims to demonstrate such a role by conducting a comparative study between Kanafani and Jean-Paul Sartre's selected plays produced in Europe such as "No Exit" and "The Flies".

The researcher divides the study into three axes; The first axis is an introduction to the existential philosophy between the European theater and the Arab theater. In the second axis, the researcher compares Sartre's play "No Exit" and Ghassan Kanafani's "The Hat and the Prophet," addressing the dialogue of the ego and the other in both playwrights' existential philosophies. As for the third and final axis, the researcher deals with how Sartre and Kanafani adapted the ancient myths, whether Greek or Arab, to serve their existential ideas. The study ends with the findings, followed by a list of sources and references.

Keywords: Existentialism, Ghassan Kanafani, Jean Paul Sartre, Albert Camus

نحو كتابة نقدية في المسرح تكثف عن دور المسرح العربي في اعادة صياغة التيارات المسرحية الغربية. شهدت الساحة المسرحية العربية دعو ات عديدة لتأصيل الظاهرة المسرحية العربية، حيث صدرت العديد من الأشكال المسرحية التي دعي من خلالها المبدعين العرب للعودة إلى الأشكال التراثية التي تحمل خصائص در امية ونوظيفها في العمل المسرحي. 
وهو ما نتج عنه ظهور بعض الاتجاهات الجديدة في مسارحنا العربية، نذكر منها على سبيل المثال لا الحصر، مسرح التسيسس لسعد الله ونوس، و المسرح الاحتفالي لعبد الكريم برشيد والتمسرح ليوسف إدريس، وغير هم من المسارح التي شكَّلت اتجاهات عربية ساهمت في بلورة نظريات نقدية جديدة لمواجهة هيمنة بعض النظريات الغربية على التراث المسرحي الإنساني. ولكن ماذا عن بعض التيار ات الفلسفية التي تم توظيفها في المسرح، ويحتفي بريادتها العالم الغربي، رغم أننا لنا دورا هاما فيها على مستوى الممارسة و التطبيق؟ أو على أقل تقدير أعدنا صياغتها بشكل مغاير عن الأصل، مما يجعلنا شركاء فيها ولسنا مقلدين لها فقط كما يظن البعض. هئ.

أولا: اشكالية البحث

تتلخص الاشكالية البحثية في محاولة الكثف عن أهم عناصر الفلسفة الوجودية في أعمال كنفاني، وكيفية نوظيف هذه العناصر للتعبير عن قضايا و اقعنا العربي.

يجيب الباحث عن هذه الاشكالية من خلال تحليل مسرحيتان لغسان كنفاني وهما: القبعة و النبي و الباب، وقد قام كنفاني بكتابتهما تعبيرا عن المعاناة من المناخ التشاؤمي الذي تسبب به الوجود الصهيوني في فلسطين، مثلما كانت تستفحل النازية وتتفشى في ساحات بلدان أوروبا أثناء الحرب العالمية الأولى والثانية، وهو ما كان سببا من الأسباب الهامة في ظهور التيار الوجودي في

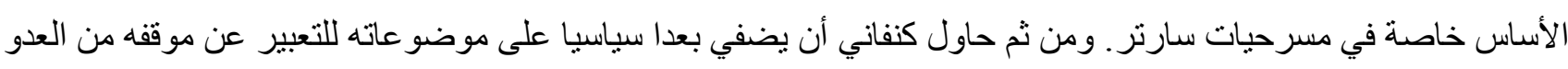
الصهيوني، ور أيه في الإر ادة الحرة والثورة والتمرد على الاحتلال. فلم يعد لكنفاني وقتها سوى التمرد للحصول على الحرية، أو التسليم بانتفاء الإر ادة الحرة.

ثانيا: أهمية البحث

1- - ابراز وتسليط الضوء على بعض النماذج المسرحية لغسان كنفاني، التي أعاد من خلالها صياغة وطرح أفكار التبار الوجودي بشكل مغاير يعبر عن خصوصيتنا وقضايانا العربية، حتى يتسنى للباحثين المهتمين بمجال المسرح من الاطلاع عليها والافادة منها، نظر الندرة الأعمال المسرحية للكاتب غسان كنفاني، حيث أنه يعد كاتبا روائيا في الأساس وبالتالي كان من المهم أن نقوم بتحليل بعض أعماله المسرحية. 2- ندرة النصوص المسرحية العربية التي تستند إلى تيار الوجودية، لذا بسعى البحث إلى اكتشاف هذا المجال الخاص بعلاقة مسارحنا العربية بالفلسفة الوجودية، فهو يعتبر مجالا جديدا بالنسبة للبحث العلمي و الدراسات المسرحية.

\section{ثنالثا: المنهج البحثي}

يتخذ الباحث من المنهج المقارن دعامة أساسية له في تحليل النماذج المختارة، حيث يسعى الباحث من خلال دراسته إلى المقاربة بين النماذج المختارة لأعمال كنفاني المسرحي، وبعض أعمال سارتر التي تبنت أفكار الفلسفة الوجودية، وهي الفلسفة التي رأى الباحث أن العالم العربي ساهم في اعادة إنتاجها من خلال المسرح. ومن ثم تتخذ الدر اسة منظور ا فكريا، 
ونقصد به الرؤية الفلسفية التي يعتمد عليها الباحث لتفسير القضية التي يتناولها بالدراسة. و إذا كان تحديد المنظور الفكري للار اسة يعد أحد الركائز المهمة والرئيسة لكونه يشكل الإطار المرجعي الموجه للباحث أثناء مضيه في دروب البحث، فقد حاول الباحث الافادة من مفاهيم الوجودية في تحليل النماذج المختارة و المقارنة بينها وبين أعمال جان بول سارتر و البير كامو في أوروبا، من خلال عدة استر اتيجيات أهمها؛ المقارنة على مستوى التيمة الخاصة بكل مسرحية، وتوضيح كيفية استخدام الكاتبين للفلسفة الوجودية لبلورة وطرح أفكار هما الخاصة، من أجل تقديمها في سياقات زمانية ومكانية مغايرة. بالإضافة إلى تنيان مو اقع و آليات النتاص بين النماذج المختارة.

\section{رابعا: المصادر المسرحية المختارة}

ـالذباب أو الندم The Flies لجان بول سارتر 1943. - ملسة سرية No Exit - مان مان بول ساتر 1946. - مسرحية الباب لغسان كنفاني 1964. -مسرحية القبعة و النبي 1967. أولا: الوجودية1 بين الواقع الأوروبي والعربي

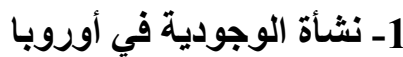

شكلت الوجودية هنفذا فنيا للمبدعين نقلوا من خلاله تجربة القلق الوجودي الذي يعيشه العالم إثر وجود النزاعات و الحروب، لذا كان من أهم إرهاصات ظهور ها الحرب العالمية الأولى والحرب العالمية الثانية، حيث عبرت الوجودية عن حالة القلق العام الذي تملك العالم وقت الحربين. فلهذين الحدثين الأثر البالغ في اشعار الانسانية بقرب النهاية وبحلول الفناء قريبا؛ لذا كانت الوجودية أصدق تعبير عن تلك الفترة الثنائكة والمتفجرة في التاريخ العالمي الحديث في أوروبا (بدوي،1980: ص 19). Soren شئت تلك الفترة المتفرة في التاريخ الأوروبي التي صعد في إثرها أعلام الوجودية، مثل سورين كور كيغارد Kierkegaard

$$
\text { من القرن العثرين، مساوئ الحروب التي خلفت ملايين القتلى ور اءها، }
$$

1 ـالوجودية تمثل حركة ثقافية في أوروبا إزدهرت في الأربعينيات والخمسينيات من القرن الماضي من خلال الانتاج الأدبي و الفلسفي

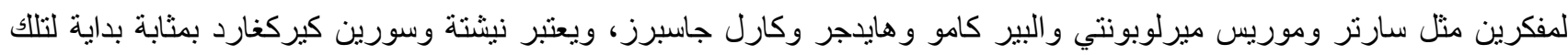

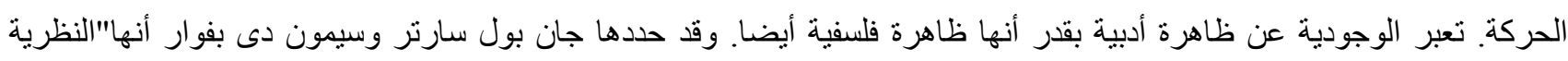
الأخلاقية التي يجب أن نتعامل مع الحرية ونعدها العنصر الأهم في تفسير جوهر الوجود البشري بإعنبار ذلك الوجود ذات قيمة جوهرية

و أساس جميع القيم الأخرى ( Stanford Encylopedia of Philosophy,2004). 
مما كان من الضروري أن يبحث مفكري ذلك العصر عن تبار أو فكر يعيد للإنسان قيمته المهدرة ويعزز أهمية وجوده الني ضاعت في ثنايا الحرب (طه، 2017). غير أن هناك بعض الكتابات الأخرى لهؤلاء المفكرون قد جنحت إلى اظهار الجانب المظلم من الحياة و هو؛ ضعف الإر ادة الانسانية والفعل البشري تحت وطأة سيطرة وتحكم القوى العليا أو سياسات المستعمر، مثل العدو النازي حينذاك في أوربا، وذلك لإيضاح فكرة انتفاء الإر ادة البشرية الحرية أو على الأحرى صراع الإنسان الأزلي مع تلك القوى للحصول على حريته.

يُعد نيتشة Nietzsche (1844-1900) الوجودي الأول الذي تناول هذه الأفكار، حيث ثار ضد المقاربات الميتافيزيقية و التقليدية تجاه الإنسان ومكانته في الكون، ومن ثم دعا إلى موت الإله في كتاباته، و انتقد الاستسلام لفكرة تحكم القوى العظمى

و المفاهيم الدينية والآلهة (Aldegheishem,2015,p:297).

على هذا المنوال يتبلور فكر سارتر الوجودي في الفكرة التالية وهي؛ أن الوجود يسبق الماهية، بعد أن كان بعض فلاسفة الوجودية يرون العكس أن الماهية تسبق الوجود، ومن هنا جاءت أفكار سارتر متمردة ومتفردة عن السائد، فقد أرسى مبدأ أن الإنسان بعد موضو عا في حد ذاته بعيدا عن العالم الخارجي، فهو من بخلق الماهية الخاصة به في الحياة بشكل حر. "فالإنسان يولد أو لا ويصادف وينبثق في العالم، ثم يتحدد من بعد. الإنسان في أول وجوده ليس شيئا و لا يمكن أن نحده، فهو كما يتصور نفسه، وكما يريد نفسه بعد أن يوجد وكما يثاء" (بدوي، 1980،ص: ولص: 262).

يطرح سارتر افتراضا محوريا في فلسفته الوجودية وهو أن الوجود يسبق الجوهر، أي أن الأفراد يولدون كائنات حية مستقلة ومسؤولة وو اعية بدون قالب نمطي أو تعريف مسبق مفروض عليهم، ثم بعد ذلك يقومون بتكوين حياتهم الفعلية وما ستكون (جو هر هم الحقيقي). بالتالي فإن البشر، من خلال و عيهم الحر، يخلقون قيمتهم الخاصة ويحددون معنى وشكل لحياتهم بعيدا عن الآلهة و العادات والتقاليد و القوانين المفروضة عليهم، ومن هنا تتكون الماهية والإرادة الحرة، وإن حدث غير ذلك فهو ينذر بضياع الحرية والإر ادة الانسانية.

على هذا الأساس، يقول سارتر في كتابه " الوجودية مذهب إنساني" الذي يعد ترجمة لـ لقاء له يدافع فيه عن الوجودية ضد ما

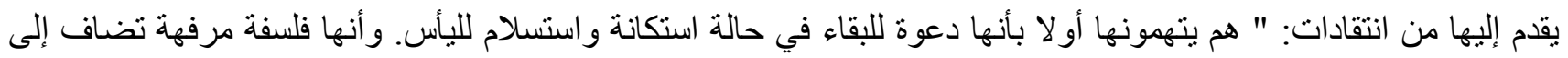
الفلسفات البرجوازية الأخرى ... فأننني أعرف الفلسفة الوجودية كمذهب يجعل الحياة الإنسانية ممكنة. كل هذه الاتهامات التي وجهت إلى الوجودية تتفق جميعها على دعوتهم إلى ألا نعارض السلطة و لا نقاوم من هم أقوى منا. و لا نتلخل فيما لا يعنينا وما ليس من اختصاصنا. هؤ لاء الناس الذين يشككون في الوجودية ويتهمونها بالتشاؤم، فالعكس صحيح، فالوجودية فلسفة متفائلة ـ لأنها في صميمهما فلسفة تضع الإنسان مواجها لذاته، حرا، يختار لنفسه ما يشاء، وهذا أمر مزعج لهؤلاء الناس" بهاء

.(Sartre,2007,p:17-23)

طبقا للأفكار السابقة ناهض سارتر الطموح الاستعماري النازي في أوروبا في الأربعينيات والخمسينيات، من خلال مسرحه الذي حمل بشكل غير مباتر اسقاطات سياسية تكثف سياسة المستمر الاستبدادية في قمع الحريات والإر ادة، وبلور ها في إطار فلسفي يوضح ثنائية الأنا (المُستعدِر ـالآلهة و القوى العليا) و الآخر (المستعمَر ـالإنسان)، 
و هو ما يؤكد أن فلسفته قد تسنوعب مضمونين؛ فلسفي: يوضح صر اع الإنسان الأبدي للحصول على حريته واثبات كينونته

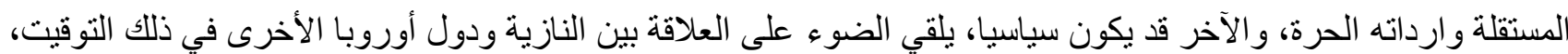
لذا كان الأمل كبير في مساندة سارنر للقضية الفلسطينية بنفس المنطلق.

على غير المتوقع سقط سارنر سقوطا عربيا كبير ا تزامن مع هزيمة العرب من إسرائيل عام 1967، ففي بداية ذلك العام زار سارتر وسيمون دى بوفوار القاهرة، ثم قام بزيارة أخرى إلى إسر ائيل نفسها، وقد وصف أدوارد سعيد الزيارة بعد ذللك بالزيارة المخيية، حيث أصدر سارتز بيانا صادما لمؤيدي القضية الفلسطينية في مجلة الأزمنة الحديثة، يساند فيه بشكل غير مباثر دولة إسر ائيل. "و هنا مُنعت كتب سارنر في العراق بشكلٍ فوري، وأُحرقت في الجزائر، وسقط الفيلسوف عربيا، وسقطت معه آمال كبيرة، وكبرت الخيبات مع خيبة هزيمة 1967، لتتعالى الأصوات، أولها صوت سهيل إدريس، لاستبدال سارتر بمفكرين

$$
\text { آخرين" (منصور، 2020). }
$$

اعتبر سارنر على غير الحقيقة أن العلاقة بين الفلسطينيين واليهود هي علاقة بين مظلوميّن، كل منهما تعرض للظلم و الاضطهاد ويجب أن يقدر كل منهما موقف الآخر، حيث أنكر حق الوجود الفلسطيني متأثر ا فيها بأحداث اضطهاد اليهود في أوروبا من الجانب النازي، ومن ثم ظهر موقفه متعاطفا بشكل أكبر مع اليهود (الحمامصي، 2016).

نتيجة للاعتبار ات السابقة، كان من الضروري أن يهب بعض المفكرين و الكتاب العرب للافاع عن القضية الفلسطينية متأثرين ببعض التيار ات الوجودية، ليتم توظيفها بشكل يندد بسياسية المستعمر الصهيوني، في موقف مشابه لما كان يفعله سارتر في أوروبا وقت الاحتلال النازي. ويقى من أبرز وأهم هؤلاء الكتاب الذين ظهروا في هذا التوقيت، الكاتب الفلسطيني غسان كنفاني (1963-1972). وهي النقطة المحورية في بحثنا، ونحاول من خلالها الاجابة عن السؤال الأهم: هل ظهر التيار

الوجودي في بعض أعمال كتاب المسرح العربي؟ وكيف تم توظيفه لخدمة القضايا السياسية العربية التي تجاهلها سارتر؟ فقد شقت الوجودية طريقها إلى العالم العربي وسيطرت على أدب النصف الأول من القرن العشرين، خاصة مع ظهور الصر اعات السياسية في فلسطين والحروب في الوطن العربي. ففي الوقت الذي سعى فيه الوجوديون الغربيون إلى الحرية وتحرير جميع الحدود، سواء كانت لاهوتية أو سياسية أو اجتماعية، ليأخذ المرء مسؤولياته وخياراته. فإن الوجوديين العرب استخدموا الفكر الوجودي لخدمة السياسة بشكل أكبر، حيث أثنار الصحفي والكاتب المصري أنيس منصور (1924-2011) في مقاله "هل نعود إلى الوجودية؟" إلى أن الوجودية هي الأيديولوجية الأنسب للعالم العربي لدفاعها عن قيمة الحرية .(Aldegheishem,2015 ,p: 298)

دعا منصور في مقاله إلى وجوب تحقيق الإنسان لحريته وتقدير وجوده كإنسان. ومضى منصور في انكار الحتمية، ورأى أن الإنسان هو من يصنع نفسه بنفسه، وذكر في مقاله سبب انتشار الوجودية في العالم العربي، الذي يعكس التجربة القاتمة للنضال ضد الاستعمار. علاوة على ذلك، أعلن منصور أن الوجودية ساعدت أوروبا واليابان على الخروج من مآسي الحربين العالميتين وتسخير قوتهما من أجل المستقبل (Aldegheishem,2015,p: 298). 


\section{2- 2- كنفاني و الوجودية العربية22}

نشر غسان كنفاني عام 1963 رواية رجال في الثمس Men in the Sun التي تتحدث عن ثلاثة فلسطينيين يحاولون عبور الحدود من العر اق إلى الكويت عن طريق مرشد فلسطيني مأجور قد خسر أرضه بفلسطين فيما سبق ويعمل سائقا لثاحنة، و لا يصل الرجال الثلاثة أبدا إلى الكويت، حيث يمونون من العطش و الاجهاد والاختناق في خزان المياة الذي قام مرشدهم بتخبئتهر داخله، ليعبر بهم الحدود بالثاحنة المحملة بالخزان دون ملاحظة الثرطة، وتتتهي الرواية بموتهم، تعبيرا عن سوء الإدارة

الفلسطينية في إدارة الأزمات عام 1948 (Di- Capua,2018, p:127).

نستشعر أيضا في الرواية بعض الملامح الوجودية وخاصة في مسألة ترك الرجال لهذا المرشد المأجور مهمة قيادتهم والتحكم فيهم وتحديد وجتهم إلى أن يصلو الحتفهم في النهاية، إذ يطرح كنفاني بشكل غير مباثر قضية التحكم في مصير الآخر عبر التوجيه الخاطئ، مما يؤدي لخسارة الرجال أنفسهم وأرضهم وحريتهم ووجودهم وحياتهم. وهو ما انعكس على مسرحه الذي يوضح تللك الأفكار و الاشكاليات وخاصة مسرحينيّ الباب التي قام بكتابتها في العام التالي لكتابة رواية رجال في الثمس، ثم وهي بعد ذلك مسرحية القبعة والنبي التي قام بكتابتها نفس عام النكسة العربية 1967. ويبدو أن كتباته الثورية لم تعجب العدو الصهيوني، حيث قام بقتله عملاء الموساد عام 1972 في بيروت (Di- Capua,2018,p: 128).

ينضح إلى حد كبير من كتابات كنفاني أن تأثره بالتيار الوجودي قد يرجع إلى رغبته في بلورة أفكاره بشكل سياسي في أعماله،

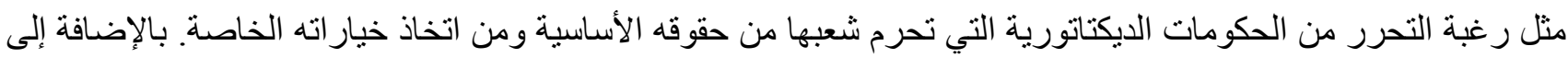
ذللك، قد تكون الرغبة في تحرير الأراضي الفلسطينية من الاستعمار والاحتلال الصهيوني، أو على أقل تقدير المقاومة والثورة ضد الاحتلال، ومن ثم كانت الوجودية أنسب الطرق للوصول لهذا الهدف.

\section{ثثانيا: القبعة والنبي وجلسة سرية وحوار الأنا والآخر بين سارتر وكنفاني}

يحاول الباحث في هذا الجزء من البحث تحليل مسرحيات غسان كنفاني التي يرى فيها نقاط تماس مشتركة مع مسرحيات سارتر الوجودية، وذلك لتوضيح أوجه تأثر كنفاني بالفلسفة الوجودية، وكيفية اعادة توظيفها داخل مسرحه، وذللك عبر عدة

2 -يذكر في ذلك الصدد أن الكتابات الوجودية العربية قد عرفت طريقها في مستهل عام 1944 عندما ناقش عبد الرحمن بدوي(19172002) أحد أبرز المفكرين والفلاسفة المصريين أطروحته التي حملت عنوان "الزمان الوجودي" وقد جمعت بين الفلسفة الظاهراتية

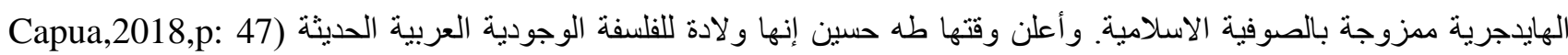


يتشابه نص سارنر جلسة سرية3 مع نص القبعة و النبي لكنفاني على مسنوى الحبكة في بعض النقاط، حيث يظهر كليهما في صورة أنببه بالمحاكمة للشخصيات الرئيسية جر اء بعض الأفعال المقيتة.

تدور مسرحية القبعة والنبي في قاعة محكمة صريحة ونجد في الإرشادات المسرحية أن كنفاني يذكر أن الديكور الخاص بالمسرحية يُفضل أن يحتوي على طاولتان متثابهتان يفصل بينهما حاجز حديدي يوحي بقفص الاتهام، و القفص مكون من

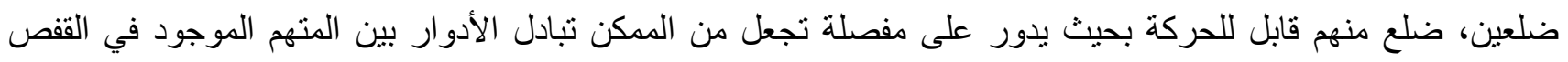
و القضاة. وهنا أراد كنفاني تتبيه الجمهور لنقطة مرجعية وهي أن كل من المتهم والقضاة يمكن لهما تبادل الأدوار، فالمتهم قد بد يصبح قاضيا والقاضٍ قد يصبح متهما. أما عن المسرحية نفسها فهي تدور حول محاكمة متهم تسبب في مقتل كائن فريد قادم من الفضاء يدعى الثيء، وقد استقر بمركبته الفضائية على شرفة المتهم الذي تبناه ورفض تسليمه إلى أي جهات علمية أو حكومية، معتبرا إياه نبيا أو رسالة كونية لا يمكن التفريط فيها، ولكنه يقصر في رعايته، ولا يقم بتزويده بالماء لمدة طويلة (الثيء يتغذى على الماء فقط) فيموت الثيء في النهاية، ويمنتل المتهم أمام القضاء الذي يحقق في الحادث وملابساته.

يستخدم سارتر في مسرحيته تقنية الاسترجاع (فلاش باك Flash Back)، حيث تسترسل كل شخصية في سرد بعض التفاصيل

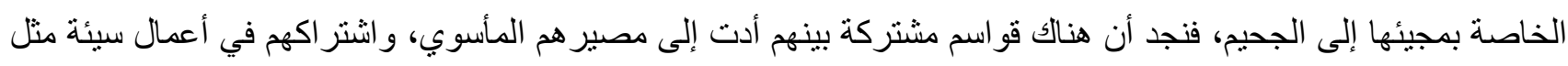
الخيانة أو المنلية الجنسية أو الهروب من الخدمة العسكرية (بالنسبة لجارسان) وبالنالي يجمعهم نفس المصير في نفس الحجرة حيث أن وجودهم لم يكن مصادفة على الأحرى. وهي التقنية ذاتها التي يستخدمها كنفاني في مسرحيته حيث أن المسرحية تبدأ بالمحاكمة وبسرد القضاة لتفاصيل الجريمة التي قام بها المتهم، فيسترسل المتهم أيضا مثل شخصيات سارتر في سرد الأحداث الماضية، حتى يبرأ ساحته في القضية عبر انكار قصدية قتل الثيء. ومن ثم تتخذ المسرحيتين طابع المحاكمة، ولكن بأثكال وطرق مختلفة توحي للقارئ بعدم وجود إرادة حرة للشخصيات المحورية في الأحداث، حيث أن كل شخصية تمثل الجلاد و المعاقب للآخر والمتحكم في مصيره. ومن ثم برفض الفكر الوجودي مسألة الاجبار، فالإنسان حين يختار، يختار بكل حرية ولا يعينه شيء آخر غير هذه الحرية. لأن الوجودية، تتفي كل احتمال لوجود قيم سابقة مسطورة نقيس عليها أعمالنا ونسترشد بها في حياتنا. فلما كان الوجود يسبق الماهية، فقد انتهى كل امكان للرجوع إلى طبيعة إنسانية مثتركة بين جميع البشر. فليس هناك مرشد وليس هناك من قاض، لبس هناك من جبرية لا من الطبيعة ولا مما فوق الطبيعة. الأنسان حر، الإنسان هو الحرية (القصاص، 2016، ص: 16).

3 تدور جلسة سرية داخل إحدى الغرف داخل الجحيم، حيث يتشارك ثلاث شخصيات الغرفة بعد موتهم، وقد قضي أن يعيشوا معا إلى

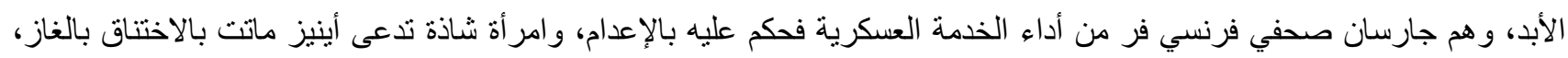

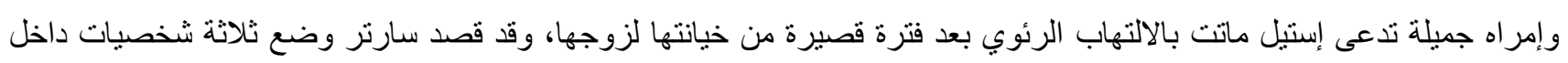
مسرحيته حتى تمثل الثخصية الثالثة دوما دور الرقيب والقاضي الذي يقمع رغبات الثنات الثخصيتين الأخرينين. 
الهجلة الدولية لنشر البحوث والدراسات

International Journal of Research and Studies Publishing
المجلد الثالث - الإصدار السادس والعشرون تأريخ الإصدار: 20 20 2021 ديسمبر 2021م

2: - الوجودية بين سارتر وكنفاني من منظور فانتازي

تبقى الفكرة الوجودية المحورية التي كان ينادي بها سارتر في مسرحيته جلسة سرية، هي انتفاء وجود الإر ادة الحرة للإنسان بسبب وجود الآخرون الذين يتحكمون في إرادة من حولهم، ومن ثم كانت مقولته الثهيرة في المسرحية "أن الجحيم هو الآخرون" تعبير اعن تلك الفكرة أن الإنسان غير الحر هو من يولا ولا يستطيع تحقيق ماهيته الخاصة بنفسه ويتكفل بتحديدها

يظهر هذا في مسرحية القبعة والنبي وجلسة سرية في أكثر من نقطة حيث تتشابه مسرحية القبعة و النبي لكنفاني مع بعض أفكار نص سارتر الجلسة سرية في علاقة الأنا بالآخر، فالثيء الذي أتى من الفضاء الخارجي بصفته كيانا موجودا لا يحمل أي ماهية بعد، يقوم المتهم بطل المسرحية طوال الوقت بقولبته وصنع ماهيته الخاصة بتحويله إلى قبعة أو نبي تعبير ا عن صنع

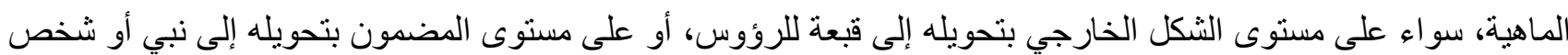
ذو كر امات. ومن ثم فالمتهم يتحكم في مصير الثيء، الذي بعد معادلا فنتازيا للإنسان المجبر و المُسبر، و هو ما يتنافى مع الفكر الوجودي، الذي يتبنى فكرة أن الإنسان الحر هو من يصنع ماهيته الخاصة بعد وجوده. ومن ثم تنتفي إرادة الثيء الحرة في مسرحية القبعة والنبي، فهو لا يتحكم في مصيره و إنما هو يتقولب على حسب رغبة المتهم ولا يستطيع الاعتر اض:

"الثيء: إنتي على أي حال لا أخسر شيئا، ولذلك لا رغبة عذدي في المعارضة الآن، ولكن يضحكني أنك ستبني كونك الجميل مبتدئا بقبعة.

المتهم: لا كن رقيقا، قبعة على رأس حماتي، نحولها أنا وأنت إلى نبي مثُلك"(كنفاني، 2015، ص: 65).

يتشابه هذ المقتطف مع حوار إينيز وإستيل في مسرحية جلسة سرية لسارتر، حيث تقوم إينيز بقولبة شخصية إستيل داخل الجحيم هي الأخرى، فعندما تبدأ إستيل في البحث عن مر آة داخل الجحيم لتعدل مكياجها فلا تجد أي مر آة، تقوم إينيز بإقناعها أنها مر آتها (المر آة هنا قد تعبر عن صنع الماهية)، ومن ثم تقوم بصنع ماهيتها عبر توجيهها بالإشار ات والكلمات، مما يؤكد رمزيا على انتفاء ار ادة استيل الحرة حيث أنها في الأحداث لا تستطيع صنع ماهيتها الخاصة في الجحيم إلا من خلال عيون إينيز، وكأن إينيز هنا تحولت إلى إله يفرض سلطته عليها: "إينيز: هذا أفضل..اتبعي خط شفتيك، انتظري سأرشد يدالك، هذا جميل ستيل: جميل تماما مثلما حضرت هنا؟ إينيز: أجمل بكثير، إن فمك يبدو شيطانا بهذه الطريقة ستيل: يا، وتقولين إنك تحبينه! كم يبدو الأمر مثير للجنون الايرى المرع نفسه" إينيز: هنايك..أنت تعرفين الطريقة التي يصطادون بيها القبرات بمر آة؟ أنا مر آتك يا عزيزتي ولن تفلتي مني"(سارتر،1958، (58: ص 
من هنا يشير سارتز وكنفاني إلى أن الإنسان فرد مستقل تماما، تحدد أفعاله إر ادته وحدها، و عندما يتنخل شخص آخر في ذلك فهو يضرب مبدأ الحرية المعصومة والاختبار الحر في مقتل وبالتالي فهو يتعرض لجحيم الاجبار وانتفاء الارادة الحرة. فجوهر الإر ادة الحرة هو أن الإنسان يصنع جوهره بنفسه ولكن الثخصيات في مسرح سارتر وكنفاني، هي التي تصنع جوهر الآخر، فكل شخصية تترك للأخرى المجال لصنع جو هر ها الخاص، لذا نتتفي الإر ادة الحرة، ومن ثم تناقش المسرحيتين فكرة الماهية و الجدوى من الحياة ولكن بمنظور فانتازي خيالي.

تعد الفانتازيا نوعا أدبيا يتحرر من قيود المنطق و الثكل، ويعتمد اعنمادا كليا على إطلاق سر اح الخبال، ويطلق على جنس أدبي قصصي تقع أحداثه في عالم متخيل، يخضع لقو انين فيزيائية تختلف عن العالم الذي نعيش فيه، ويتتاول شخوصاً غير واقعية وخيالية محضة وغرائبية غالباً، أو يصور عالماً يخضع لقوانين لم تكتشف بعد، أو قوانين نتناقض مع تجربتنا الواقعية الحاضرة4. تستعرض الفانتازيا قصة مستحيلة في العالم كما نتصور ها أو ندركها، لكنها ستكون ممكنة وفقا لثروط عو الم أخرى. (Clute \& Grant,1999,p:viii).

ويبقى الاختلاف بين الفانتازيا والخيال العلمي على سبيل المثال في أن الخيال العملي له امكانية التحقق ويعتمد في الأساس على حقيقة علمية، بينما الفانتازيا هي تعبر عن عوالم غرائبية ليس لها أي تحقق في الواقع. فالفانتازيا خيال يثير الدهشة ويحتوي علي عنصر جوهري و غبر قابل للاختز ال وخارق للطبيعة و على عو الم أو كائنات أو أنشاء خارقة للطبيعة أو مستحيلة

.(Manlove,2014,P: 206)

وبنطبيق عناصر الفانتازيا على مسرحية كنفاني، سوف نكتشف أنه قد تعامل مع مسرحيته وشخوصه بمنطق أدب الفانتازيا المناقض للو اقع، حيث لم يتم اثبات بالدلائل وجود أي كائنات فضائية أو كائنات عاقلة أخرى غير الإنسان، ومن ثم يكسر كنفاني جميع المسلمات الواقعية في عالمنا، ويؤلف حوارا افتر اضيا بين إنسان وكائن فضائي، يأخذنا من خلاله إلى عالم متخيل ميتافيزيقي لا وجود له في الو اقع، ليعبر عن مضامينه الوجودية في فقدان التو اصل و الغربة بين القادة والثعب الفلسطيني، ومن ثم ستكون نتيجته هو ضياع الأرض في النهاية مثلما يموت الثيء في المسرحية. ولعل لجوء كنفاني لمثل هذه الحبكة الفانتازية محاولة منه أيضا للهرب من الرقابة الصهيونية على أعماله، عبر تقديم قضية الصراع الفلسطيني الاسرائيلي في إطار لوحة فانتازية خيالية في الظاهر، لكنها تحمل معان سياسية ثورية في الباطن؛ لتكون باعثة على التفكير الثوري.

على مستوى آخر يأخذنا سارتر إلى عالم الجحيم في مسرحية جلسة سرية بشكل مغاير عن تصورات الجمهور للجحيم في عالمهم الو اقعي. الجحيم عند سارتر ليس به أدوات تعذيب أو نار أو شياطين كما يتصور البعض و إنما هو الآخرون كيفما أراد، و هو ما يتعجب منه جارسان في بداية المسرحية عندما يتحدث مع الخادم الذي يلبي طلبات السجناء، حيث يكتشف جارسان أن شكل الجحيم المتعارف عليه في الحياة الو اقعية لا يتو افق مع ما بر اه في الغرفة. ومن ثم فهو تصور خيالي للجحيم.

4 -تم الاستعانة بتعريف ريما الحكيم للفانتازيا في مقال بعنوان "الفانتازيا في الأدب" من الموسوعة العربية Arab Encyclopedia. تم http://arab-ency.com.sy/detail/8909 : الاستخر الاج من 


\section{3: اللا جدوى بين ساتر وكنفاني}

تنتهي المسرحيتين بشكل يؤكد لا جدوى الحياة وعدم امكانية الحصول أبدا على الحرية، إذ أن المكان المسرحي من بداية الأحداث في كلتا المسرحيتين يؤكد على المعنى السابق، وهو انتفاء ونفي وجود الحرية والإرادة، حيث أن سارنر أختار غرفة مغلقة داخل الجحيم لهذا الغرض، لا تحيل ذهنيا إلى الجحيم بشكله التقليدي المتعارف عليه في الكتب و الديانات، إنما كانت أثبه بمثابة السجن الذي سيظل فيه أبطال الحدث إلى ما لا نهاية لا يستطيعون الخروج منه.

تصل الثخصيات في نهاية الأحداث إلى محاولة قتل بعضهم البعض حيث تسعى إستنل لقتل إينيز حتى تترك لها المجال الحر لإقامة علاقة مع جارسان، ولكنها تتفاجئى أن إينيز ميتة بالفعل ومن ثم سوف تظل عملية التلل مثل الدائرة المغلقة لا جدوى منها، وهو ما يصدمهم جميعا في نهاية المسرحية أن الجحيم الخاص بالآخرون لا مفر منه وسيقى إلى ما لا نهاية. وهنا نرى كيف تم انتزاع الحرية من أبطال المسرحية للارجة التي لا يملك أي منهم رفاهية قتل نفسه أو قتل الآخر، فالكل مجبر على المكوث معا إلى الأبد في جحيمهم الخاص.

أما مسرحية كنفاني التي تدور داخل ققص زنزانة بالأساس يتبادل فيه المتهم وهيئة المحاكمة الأدوار (الجاني والقاضي) عن طريق حيلة مسرحية وهي تحريك الدائرة المستديرة فيما بينهما، فتؤكد بشكل مباشر وجود الإنسان داخل سجن الحياة طيلة العمر حتى لو ظهر عكس ذلك على المستوى الظاهري، فحتى هيئة المحاكمة التي من المفترض أنها تمتلك الصلاحيات في قمع حرية و الحكم عليه بالسجن، إلا أنهم داخل القفص مثله لا يمتلكون الحرية أو الإرادة المطلقة أيضا، وهو ما ينشابه مع فكرة جلسة سرية التي تلعب فيها كل شخصية دور المر اقِب و المر اقَب في نفس اللحظة ومن ثم يصبح الجحيم هو الآخرون في عالم يخلو من الحرية المطلقة سواء كنت داخل القفص أو خارجه.

ويقى استخدام فكرة اللاجدوى داخل المسرحيتين يتم بغرض مختلف حيث أن سارتر قد قام بطرح فكرة لا جدوى الحياة للتأكيد على معانٍ فلسفية بأن الإنسان لا يمتلك الإرادة الحرة ومن يصبح الوجود عبثيا، بينما يغلف كنفاني وجوديته بشكل سياسي

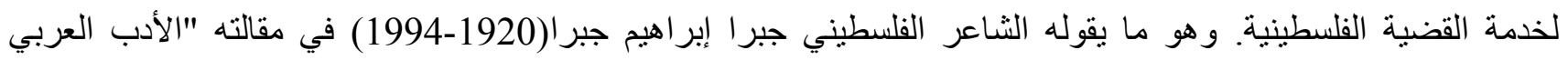
الحديث و الغرب" (1971)، موضحا من خلاله الأثر الكبير للفلسفة على العالم العربي. فقد بدأ مقالته باستكثاف تطور الأدب العربي عبر القرون، و التأثير القوب للأدب الغربي على الكتابات العربية المعاصرة. وتعليقًا على الوجودية، قال جبرا: "ليس بله على المرء أن يو افق على كل ما قاله سارتر، لكن أفكاره أصبحت محورية للجيل الجديد من الكتاب الذين سعو اللمشاركة في القضايا السياسية والاجتماعية في عصر هم، فهي محاولة للحفاظ على الفكرة العامة وحصر ها في السياقات السياسية بعيدًا عن جو هر ها الفلسفي" (Aldegheishem,2015,p:298).

طبقا لذلك الطرح يقدم كنفاني في مسرحيته القبعة والنبي بعض الرموز التي تؤكد أن الهدف من كتابة المسرحية وفلسفتها هو سياسي بحت، حيث نسنطيع القول أن اللاجدوى تتمثل في ضياع السلام والأرض و الاستقر ار بضياع الأر اضي الفلسطينية، 
إذا اعتبرنا أن المتهم قد يمثل القادة الفلسطينيين حينها وأن الأر اضي الفلسطينية تتمثل في ذلك الثيء الغامض الذي كان بمثل الحياة كلها للمتهح وير غب كل العالم والمؤسسات العلمية الكبرى في الحصول عليه، لكنه قام بقتله بشكل غير مباشر عندما أهمله، ولم يعيره الاهتمام الكافي على الرغم من قيمته الكبيرة له حيث يقول في المسرحبة أنه عالمه كله:

\section{"المتهم: أنت الثيء الوحيد في عالمي..بل أنت عالمي في الحقيقة(كنفاني، 2015، ص: 39 ).}

ومن هنا نرى كيف قد قام كنفاني بتطويع الفكر الوجودي من الأجل الاسقاط السياسي على قضية بلده، لكنه استخدم أسلوب الفانتازيا واللا معقول في كتابته حتى يتم تصنيف المسرحية أنها مسرحية فنتازية، ومن ثم يستطيع التملص من الرقابة، ولكن بالنظرة المتأنية للموضوع سنجد أن المسرحية قد تدعو إلى ظهور نوع مسرحي جديد في الوطن العربي، قد نطلق عليه الوجودية السياسية وليست الفلسفية فقط، وهي وجودية تستهدف في الأساس مُسائلة النظم الحاكمة في الغرب وقادة الاحتلال وحتى قادة فلسطين المتقاعسين عن الثورة، وكل هذا في إطار فانتازي سياسي وجودي، في باطنه يبدو أنه يناقش النواميس الكونية، ومسألة الاختبار و الاجبار، وفي باطنه يحمل انتقادات سياسية مباشرة لجيوش الاحتلال الإسر ائيلي.

أما هيئة المحاكمة فقد تعبر عن المجتمع الدولي المنواطئ بشكل كبير في القضية الفلسطينية، فلم يكن المجتمع الدولي على مسافة الحياد بين الطرفين، فقد كان متحيزا للجانب الإسرائيلي بشكل أكبر وخاصة سارنر نفسه الذي يعتبر الأب الروحي للوجودية، ومن ثم حاول كنفاني أن يبلور وجوديته بشكل سياسي لخدمة قضية بلده، مستعرضا هموم الوطن العربي مثل الثقاء الذي خلفه وجود الاستعمار و غياب الثمس وضياع الأمل، و هي رموز دلالية تؤكد على العزلة و الوحدة و الثقاء و المعاناة من

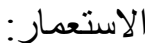

\section{"المتهم: هل هناك ما هو أكثر رعبا في حياة إنسان كان يخبئ الحب في جيبه كسلاح للافاع عن نفسه؟}

\section{رقم 1: للافاع عن نفسك ضد من؟ هل كان ثمة من يتهددك؟}

المتهم: كل الناس، كل شيء. الغربة والوحثة والوحدة. المرض والثقاء. الثقاء الذي لا ينتهي وفرص السعادة التي لا نستطيع أن نملأها. العمل والبطالة. الانكسار. الفشل. غياب الشمس وغياب الصديق وغياب الدهشة. الموت"(كنفاني،

(18:ص، 2015

يصور المقتطف السابق من المسرحية، معاناة الإنسان من الغربة والمرض و الثقاء والانكسار، في ظل الظروف الثائكة التي عاش خلالها كنفاني وجميع المبدعين وقت الاحتلال الاسر ائيلي في الستينيات، وهي الظروف التي تزامنت مع نكسة 1967، مما خلّف داخل نفس المواطن العربي، الإحساس بالحزن والفثل والانكسار ، و انتظار الموت. وهو ما يوضحه كنفاني من خلال كلماته؛ مثل غياب الثمس التي تعد تعبير ا رمزيا عن غياب قيم العدل والحق والخير في المجتمع العربي إبان النكسة. يجسد كنفاني معاناة الإنسان العربي وقتها من خلال أفكار اللاجدوى وهو ما يظهر على وجه التحديد في مقتطف: "الثقاء الذي لا ينتهي وفرص السعادة التي لا نستطيع أن نملأها" الذي يؤكد على استمرار الثقاء في حلقة دائرية مغلقة لا يستطيع أي فرد الخروج منها. وينهي مقتطفه بكلمة الموت للتدليل على أن الإنسان سيموت في شقاء ودون الحصول على السعادة، 
فهو يكثف عن عدم جدوى الحياة في ظل الظروف المحبطة التي لا يسنطع أن يقف حائلا دون حدوثها وبالتالي فهو غير حر، و هنا يكتشف أن جميع قيم العدالة و الحرية في المجتمع تتهاوى و أنها مجرد قيم زائفة.

و هو يعد تتاصـا مع أفكار البير كامو 5 في مسرحيته الثهيرة كاليجو لا6 التي عبرت عن فلسفته الوجودية، بأن الإنسان يموت وهو محروم من السعادة، دليلا على لا جدوى الحياة في فلسفة كامو الوجودية، وهو ما يقوله كاليجو لا عندما يكثف لصديقه هيليكون

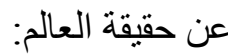

\section{" هيليكون: ما هي إذن الحقيقة يا كايوس؟}

\section{كاليجولا: يموت الناس وهم ليسوا سعداء" (كامو، 1997، ص :22).}

Julia لكثف المقتطف السابق عن تناص نص كنفاني مع أفكار كامو في نص كالجيولا، وذلك بمنظور جوليا كرستيفا kristeva و السياسة ويسعى إلى إعادة صهر ها، ومن ثم طرحت فكرة تفاعل النصوص7 مع بعضها. "إن كل نص هو عبارة عن "لوحة فسيفسائية" من الاقتباسات وكل نص هو تشّرب وتحويل لنصوص أخري، فالتناص عند كريستيفا أحد مميزات النص الأساسية التي تحيل علي نصوص أخري سابقة عنها أو معاصرة لها"( مزر ائي، 2011).

من هذا المنطلق نلتمح الصلة القوية بين مقتطفات كامو وكنفاني في أعمالهما، فكليهما يعبران عن الاضطراب الوجودي ومر ارة الحياة و عبث الكون، كلاهما يزخر مسرحياته بمعاني الوحشة و الوحدة والسأم، كلاهما قد يرى أن الحب انتفى من العالم فتحول إلى جهن على الأرض، وذلك بالنظر إلى توقيت معاصرة كامو لأحداث الحرب العالمية، ومعاصرة كنفاني للاحتلال الصهيوني ونكسة 1967. ولكننا نسنطيع القول بأن هناك بعض الاختلافات في أهداف الكتابة على نهج المدرسة الوجودية بين

5ـ ألبير كامو فيلسوف وجودي وكاتب مسرحي وروائي فرنسي ولا عام 1913، وتوفى عام 1960. اسلوبه المسرحي كان معبرا عنن فلسفته الوجودية التي تقوم على عنصرين؛ اللا معقول والثورة (التمرد)، العنصر الأول قام بمعالجته كامو في رواية سيزيفوس. أما ولام العنصر الآخر تحقق في كتابه المتمرد. سيزيفوس يمثل شقاء الانسان في الحياة دون جدوى، فهو يحمل صخرة إلى قمة جبل وما إن لبث أن يضعها فوق القمة تهبط مرة أخرى، فيهرول خلفها ليحملها مرة أخرى (بدوي، 1980، ص: 106 ). ومن ثم فإنه يكرر ما يفعله يوميا، وينتهي به الحال إلى الموت و الفناء في النهاية ،فيسأل نفسه ما جدوى الوجود؟ وهو ما يتشابه بشكل كبير مع ما يقوله المتهم أن الإنسان سوف يظل في شقاء دون أن يحصل على السعادة.

6ـ تدور مسرحية كاليجو لا في أربعة فصول، تبدأ الاحداث بالفصل الأول الذي نعرف من خلاله حادثة موت دروزيلا عشيقة وأخت الملك

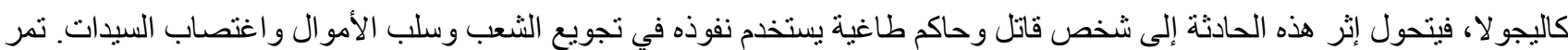
الأحداث بعد الفصل الأول بثلاثة سنوات يمارس في خلالها أثد أنواع الطغيان على شعبه الذي يثور في النهاية ويقتله في المشهد الأخير.

7 -يقصد هنا الباحث بالتناص؛ آلية التفاعل بين النصوص وبعضها. حيث لا يوجد تطابق بين نصوص كامو وكنفاني من حيث الصياغة أو

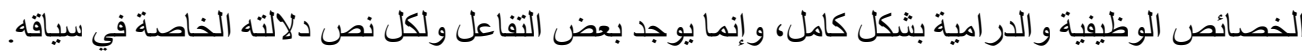


العالم الغربي وبين العالم العربي. على الصعيد الغربي، كانت محاولة أكثر لتحرير الإنسان من كل الحدود التي تسبطر عليه، استدعاء للتحرر الفكري واللاهوتي كذلك. بينما استخدمه الكتاب العرب بطريقة مقلوبة كوعد لتحرير العرب من التقاليد الاجتماعية والسياسية المهيمنة. إنهم يدعون إلى اتخاذ إجراءات لتغيير بيئتهم اليائسة الناجمة عن القضايا السياسية، ومقاربة و اقعهم الاجنماعي العبثي و انتقاده (Aldegheishem,2015,p:300).

\section{ثالثا: الأباب والباب: الوجودية بين الأساطير الإغريقية والعربية}

يتجه كل من سارنز وكنفاني إلى تغليف أعمالهما الوجودية بغلاف الأساطير القديمة، فيستخدم سارتر الأساطير اليونانية القديمة، وخاصة أسطورة أوريست و أسطورة الكتر ا، ليطرح معالجة جديدة للأورستيا الخاصة بالكاتب الإغريقي إيسخيلوس و المستندة إلى الأساطير السابقة، وذللك ليوضح أفكاره الوجودية والسياسية في مسرحية الذباب، بينما يعتمد كنفاني على أسطورة عربية قديمة تعبر عن خصوصيتنا العربية، و هي أسطورة قوم عاد ومدينة إرم القديمة.

\section{1- معالجة الأساطير لخدمة الأفكار الوجودية}

من أهم أفكار سارنر الوجودية هو أن يتحرر الإنسان من أي معتقدات، فالإنسان عند سارنر هو الوحيد الذي له حق الاختيار الحر. و لا يحق لأي قوى أخرى أن تجبره على فعل شيء دون ار ادته. "ومن هذه الفلسفة، ومن هذا الجدل الذي يبدو عنيفا في

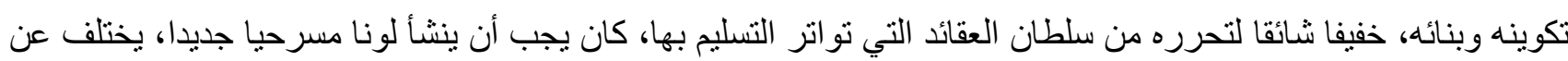
المسرح الإغريقي الذي كان يصور القدر بصورة ار ادة الآلهة المطلقة التي لا راد لقضائها، أو بصورة سُنة الكون التي لا تقهر و التي ينبخي النزول على حكمها والخضوع لنواميسها" ( فام، 1964، ص:160 ). وعلى ذلك اختار سارنر الأساطير الإغريقية التي تبجل الآلهة، ليصنع معالجة يعارض أوريست فيها الإله جوبيتر ، ولا يخضع لأوامره التي تحسه على الندم و الخضوع.

تبدأ مسرحية الذباب أو الندم بعيد الموتى الذي ابتدعه إيجست لسكان أرجوس، ليصرفهم عن التفكير في فعلته وجريمنه، ففرض عليهم يوم يُفتح فيه الباب المؤدي للمقابر مرة كل عام، لتعبر أرواح الموتى وسط الأحياء، ويصرخ الأحياء طالبين الصفح من الموتى. وهكذا ليظل الأحياء دائما أسرى الندم وطلب السماح. بينما تتنظر الكترا عودة شقيقها أوريست لينتقم من أمها كليتمنستر ا، و عشيقها إيجست. و عندما يحين ذلك ويتمكن أوريست من الانتقام وقتل الأم والعشيق، يتسرب الندم إلى نفس الكتر ا، بعد ما ألح عليها جوبيتر بأنها لابد أن تشعر بالندم على فعلتها. بينما لم يتمكن جوبيتر من أوريست الذي يصمح على أن لا يشعر بالندم. وشخصية جوبيتر هي مفتاح المسرحية، وأساس المعالجة، فجوبيتر إله الذباب و الموت الذي يملأ أرجوس بالذباب ويجبر الناس على الندم، ولم يكن من شخصيات مسرحية الأورستيا التي قام بكتابتها الكاتب إيسخيلوس في القرن الخامس قبل الميلاد، ونتشمل ثلاثية (أجامنون-حاملات القر ابين_الصافحات).

أما مسرحية الباب فيعتمد كنفاني على معالجة أسطورة عربية عاد القديمة، بقليل من التصرف في الأصل. عاد هو ملك قبيلة تسكن الأحقاف، كما يذكر المؤرخ العربي ياقوت الحموي (574- 626 هـ)، 
وكانت لهذه القبيلة آلهة وفقا للطبري: صدا - صمود ـ هبا. وعاد هو الحفيد الثاني لنوح، وهو ابن عوص ابن ارم ابن سام ابن نوح. الأسطورة غير مثبتة تاريخيًا بشكل مفصل، وكل المصادر بالإضافة إلى آيتين من القرآن عامنين، تقتصر على ما قاله الحموي في معجم البلدان، والطبري في مطلع تو اريخه ( كنفاني،2014، ص: 5-6 ). أصاب قبيلة عاد القحط الثديد بسبب

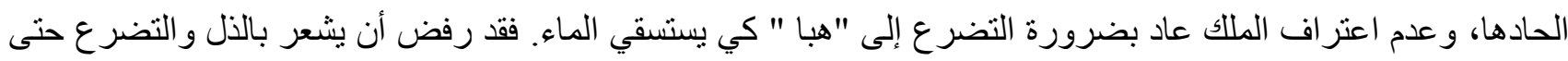
بعطيه الإله هبا الماء. فيرسل عاد وفدا إلى مكة فيه قيل ولقمان كي يستسقي الوفد الماء من مكة، ولكن الوفد يذهب إلى مكة ويتضرع لآلهة الأحقاف صدا وصمود و هبا بدلا من آلهة مكة. فيعلم عاد ويُقبِل على محاربة هبا ويلقي حتفه إثر ذلك. ويخلفه ابنه شداد الذي يكمل مسيرة عاد ويحاول تحقيق حلمه في دخول مدينة إرم ذات العماد، التي شبدها وجعلها جنة على الأرض الن النه ليخالف الآلهة و لا ينتظر منهم ثواب أو عقاب. فقد جعل لنفسه ثوابه على الأرض. ولكنه يُقتنل دون الوصول إلى هذه المدينة،

$$
\text { ليتبع مسيرته ابنه مرثذ و هكذا. }
$$

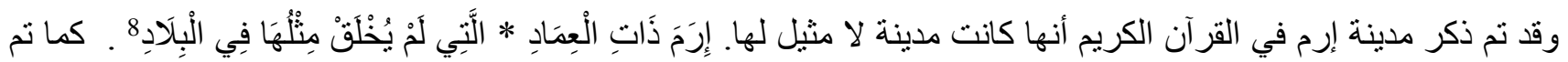

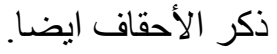

\section{2-الاسقاط السياسي}

نلاحظ في مسرحية الذباب لساتر أن بها جوانب سياسية أخرى غير الافكار الوجودية، فقد كان هناك بُعدا سياسيا يتوارى وراء

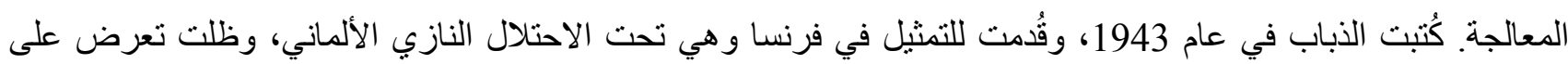

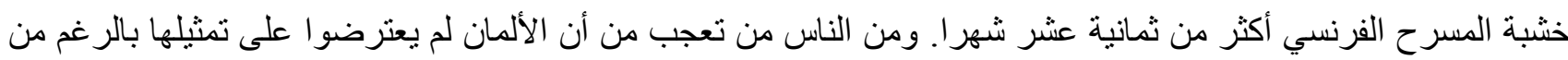
خطورة هدفها، وقد قيل عن هذا، أن رجال الرقابة النازية قد شغلوا بمضمونها الميتافيزيقي عن مضمونها السياسي، إلى أن نبهـم معاونوهم من الفرنسيين إلى هذه النقطة فأوقفوا تمثيلها (القصاص، 2016،ص:27). الذباب مسرحية مقاومة، وسارتر أراد بها أن يسند أعمال رجال المقاومة ضد المغتصب النازي من قتل وتخريب، فثبه دين التوبة لدى أهل أرجوس بسلوك حكومة فيثي الفرنسية9 في اقرار ها بأن على الفرنسيين أن يكفروا عن أخطاء آباءهم وساستهم، كما اعتبر إيجست رمز ا للألمان المغتصبين - لاغتصابه عرش أجاممنون - وكليتمنيستر ا رمزًا للفرنسيين المعاونين مع الألمان ـ لتسهيلها عملية الغدر و الخيانة - و هكذا يتيح سارتر لأوريست أن يقتل الملك المغتصب و أمه الخائنة، ولو كان ذلك ضد قو انين أرجوس ودين أهلها، كأنه يبرر

8ـ سورة الفجر من الآية الخامسة إلى السادة. النص به تتاص مع القران الكريم في الآية المذكورة وذلك للإحالة لصفات مدينة إرم المذكورة بالقران.

9 -حكومة فيشي هي الحكومة التي أصبحت في فرنسا تحت حكم نظام المارشال فيليب بيتان Philippe Pétain، إثر الهزيمة التي لحقت بها من قبل ألمانيا النازية وحتى تحرير الحلفاء لها في الحرب العالمية الثانية. وقد قاموا بالتعاون مع الألمان فيما بعد لعمل هدنة معهم، فثار الثعب الفرنسي عليه. 
الهجلة الدولية لنشر البحوث والدراسات

International Journal of Research and Studies Publishing
المجلد الثالث - الإصدار السادس والعشرون تأريخ الإصدار: 20 ديسمبر 2021م

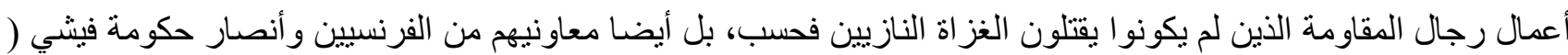
القصاص، 2014،ص: 39 ).

كذللك تظهر في معالجة كنفاني للأسطورة سمات الوجودية التي جعلت الثخصيات (عاد وشداد ومن بعدهما مرثد) تتحدى الآلهة، في قناعة تامة أن الحرية والإر ادة الحرة لا يمكن اكتسابها من الخارج ولكنها تتبع من داخل الكيان الذاتي للإنسان، وبالتالي فإن تحقيق حلم الجنة على الأرض لا يتطلب سوى الاختيار الحر، ومعارضة أب قوى أو كيانات أخرى تريد أن تقمع حريته. ولكن لا ننسى أن أغلب كتابات كنفاني كان لها مغزى سياسي. فالمقاومة عند كنفاني هي الأولوية. ويمكن فهم مغزى المسرحية عندما قام شداد بإكمال مسيرة الأب عاد، ومن بعد شداد نرى مرثد يتبع نفس الخطى، كمحاولة من كنفاني لقول أن

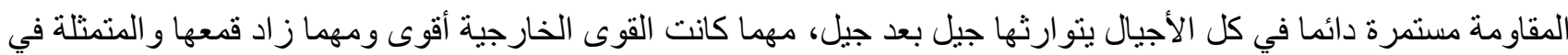
العدو الصهيوني الذي يعادل موضوعيا الآلهة التي تفرض سيطرنها على الإنسان، كيفما تناول سارتر فكرة مقاومة الثعب

$$
\text { الفرنسي للنازية وحلفائها في فرنسا. }
$$

يُقتل عاد دفاعا عن حريته ضد القوى العليا عندما يقاوم فرض سقي الماء المشترط بالطاعة والذل وفضل الحرب. ويتبعه ابنه شداد ويُقتل في أعقاب تحقيق حلمه ومواجهة القوى العليا و الوصول إلى جنته، ومن بعدهما مرثد ابن شداد، الذي يتبع نفس منهج المقاومة ولكن لا يخبر أحدا. يظهر من كلامه أنه سيسلك نفس الطريق الذي سلكه جده ووالده في مقاومة هبا. فلم يعد يؤمن بها لأن هبا لم يترك و الده أن يصل إلى إرم، لأن هبا قتله بسبب تحديه، فلا يجد فرقا بين هبا وبين أي رجل آخر. ويقول مرثد لجدته:

"مرثذ: حين كان أبي هنا يحكي لنا عن جنته كنت أقول لنفسي إن جنة هبا لا بـ أن تكون أروع، و إذا كاتت أروع، فمن الطبيعي أن يتركه يكتشف ذلك بنفسه، يتركه يرى كم هي سخيفة الجنة التي يبنيها الإنسان أمام الجنة التي بناها هبا .. ولكنه لم يتركه يكتشف ذلك. لم يتركه .. لماذا؟... لأنه لا توجد ثمة جنة ..و إذا كانت هناك واحدة فهي لن تعطي التعويض الجدير بعذاب الحياة ..لقد خاف هبا أن يكتشف شداد ذلك. الأم: إنك تتجه في نفس الطريق .. تبدأ من بدايته التي شادها أبوك، كلا .. البداية التي شادها جلك نفسه"(كنفاني، 2014، ص: 43). يوضح المقتطف السابق زيف الآلهة وكذبهم حول الجنة، حيث أن هبا يسوق الثعب ويتحكم به عبر اغوائهم بالجنة غير الموجودة بشكل فعلي، فلا يوجد في هذه الحياة سوى العذاب و الثقاء الذي يعاني منه الإنسان تحت وطأة النواميس و الأنظمة المستبدة ومن ثم يجب على مرثذ الثورة على كل هذا والمواجهة حتى لو مات في سبيل ذللك، فالثورة قد تعطي أملا للحرية،

10 -يظهر هنا التناص بين أفكار كنفاني الوجودية و أفكار كامو في مسرحية كاليجو لا في نقطة التمرد. فمرثد يكثف لجدته زئه زيف الآلهة

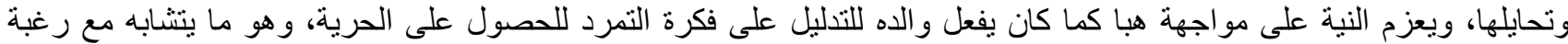

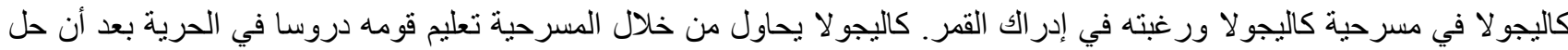

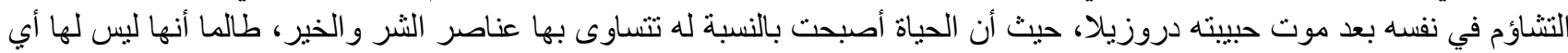


الهجلة الدولية لنشر البحوث والدراسات

International Journal of Research and Studies Publishing

ISSN: 2709-7064
المجلد الثالث - الإصدار السادس والعشرون تأريخ الإصدار: 20 ديسمبر 2021م

ولذلك فهو يريد مجابهة هبا، كأنه يبغى الثورة على المعتقدات والافكار الاستسلامية التي تسلم بالخضوع والامتثال للآلهة أو العدو الصهيوني.

\section{3-الابباب والجفاف.. عقاب الإرادة الحرة وصراع الآلهة مع الأجيال المتعاقبة}

في كلا المسرحيتين هناك صر اع الأنا / الآخر، والآخر يتمثل في صورة القوى العليا والآلهة. ولأن ارادة الإنسان الحر لا تخضع لأى قمع خارجي. فنرى في مسرحية الذباب أن جويبتر إله الموت و الذباب ينشر الذباب و الدم والضفادع كعقاب لجريمة ولة ولية قتل أجاممنون، ولجلب الندم على كل سكان أرجوس لكيلا يتحرروا من اللعنة والندم:

"أوريست: أهذا هو العدل؟ حوائط ملطخة بالاماء، وملايين من الذباب، وقيظ لافح،

وشوارع مهجورة قاحلة، وإله له سحنة قتيل، وحشرات في عقر دورها

تقرع صدور ها من سطوة الإرهاب. وهذا الصياح، هذا الصياح الذي لا

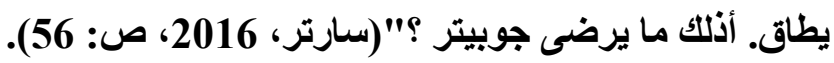

كما نرى في مسرحية الباب أن الاله هبا قد فرض الجفاف على الأحقاف، فلا يوجد سقي ماء إلا فى حالة التضرع له وطلب الندم و التوبة و الغفر ان. وأن ييتعد شداد عن حلمه في مدينة إرم التي بناها لتمثل الجنة على الأرض و التي تعتبر جريمته، ولكنه يستمر في المقاومة، و هو ما يشكل تناصا مع مقتطف سارتر السابق في نص الذباب، فهو يحيل إلى مدلول مغاير بالنسبة للسياق العربي و الهدف من قوله ولكنه يتقاطع خطابات نص سارتر في علاقة البطل بالآلهة:11:

"قيل: إنه يعتقل بإن الإله يجب أن يسقى شعبه، لقد قال لي بأن الخطيئة، أي خطيئة

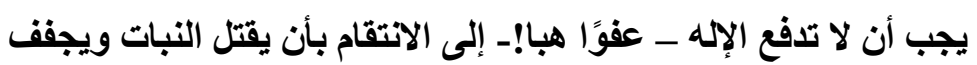

$$
\text { الضروع ويزرع الجوع. }
$$

رعد: ولماذا لم يطلب غفران هبا فيعطيه الماء؟

قيل: أنت تعرف لماذا ... أنه يعتقد أن طلب الغفران ذل"(كنفاني، 2014، ص: 10).

جدوى. فالنهاية معروفة وهي الموت، ومن هنا يتحول إلى رجل الإرادة المطلقة التي تتحدى ارادة الآلهة بمحاولة الثورة والتمرد. وبالر غم

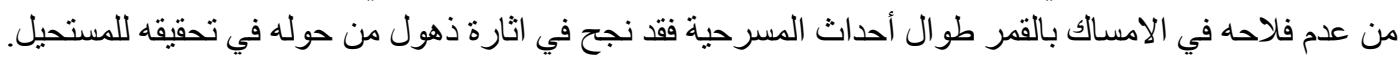

11 ـتستعرض كرستيفا في كتاب "علم النص" تحليلها للتداخل النصي في فضاء اللغة الثتعرية قائلة "يحيل المدلول الثعري إلى مدلو لات

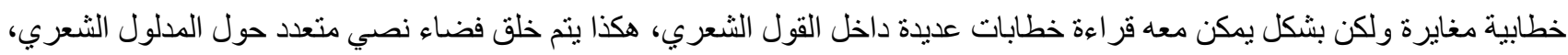

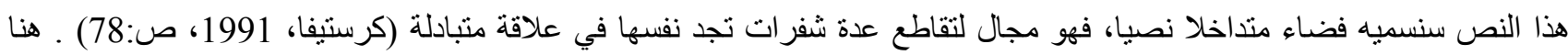

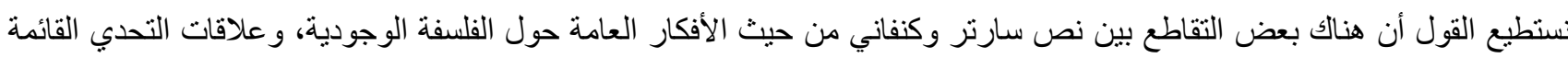
بين بطل العمل والآلهة للثورة على المسلمات والأفكار المترسخة، وهو ما يظهر في المقتطف الخاص بالحوار بين جوبيتر وأورستيس ويقابله الحوار بين قيل ور عد. 
فالجريمة نوعان. النوع الأول؛ هو الجريمة التي تطيب للآلهة وتروقهم، تلك الجريمة التي يصحبها الندم وتعقبها التوبة وتزكي في القلوب لونا من التقوى الصادرة عن الخوف و الفزع. ويقينا أن هذا اللون من الجريمة لا يمكن أن يتحرر معه الإنسان، أما النوع الآخر فهو الجريمة التي يقدم الضمير على اتيانها مسرورا منتشيا (فام، 1964 ص: 171) ـ ونرى أن كلا من سارنر وكنفاني في مسرحيتهما صنعا البطل المتمرد في مواجهة الآلهة دفاعا عن الإرادة الحرة وحق الاختيار. فنرى أوريست عند سارتر يثور على جوبيتر رافضا التوبة والندم، بينما تقتنع الكتر ا ويتسرب الندم والخوف إلى نفسها. ونرى عاد وشداد عند كنفاني في مو اجهة هبا ومحاولة الثورة ضده و اعلان الحرب لتحقيق الحلم ولإثبات الإر ادة الحرة. فنجد سارتر فى مسرحيته فى حوار البطل مع الآلهة: "جوبيتر: لست مليكك، أنت، أنت أيتها الدودة الخالية من كل فطنة. ولكن من خلقك؟ أوريست: أنت. ولكن كان يجب ألا تخلقني حرًا. جوبيتر : أنما وهبتك الحرية لخدمتي. أوريست: هذا جائز، ولكنها انقلبت ضدك، ولا حيلة لي ولا لك في ذلك" (سارتر،2016، ص :1846).

كذللك نرى أن كنفاني رسم شخصية البطل شداد الذي ينشد حلمه ويعارض هبا إله الأحقاف لأنه يرى أنه حر ويصنع حلمه وغايته بيده، فنرى حوار شداد مع أمه:

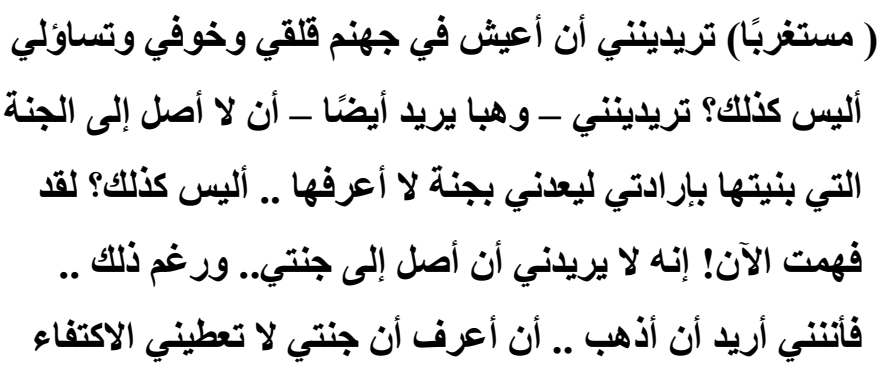

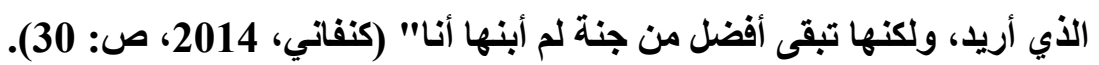

نلاحظ من السابق كيف يمكن تفسير الرموز في المقتطف بشكل سياسي، حيث قد تمثل الآلهة الديكتاتورية في المسرحية الكيان الصهيوني الذي يقمع حلم الفلسطينيين في الحرية، وفي استرجاع الأراضي الفلسطينية المغتصبة التي تمثل الجنة والوجود بالنسبة لهم، ولكن شداد يجابه هذا الظلم معبر ا عن ثورة الثعب الفلسطيني المستمرة التي لا تخمد شعلتها ضد هذا الاستعمار للأرض و الكيان الفلسطيني. حيث تتغلف وجودية كنفاني في شكل المقاومة ضد الظلم و العدوان، وهنا تتجلى المعركة لمصلحة الإله هبا في البداية وتأخذ مقاومة سلطته أبعادا زمنية، عبر تتابع الأجيال في الثورة على هبا، كما يحدث في الثورة والمقاومة الفلسطينية حتى وقتنا الر اهن. ومن ثم فإننا نجد تسليم راية المقاومة من عاد إلى شداد، ثم مرثد كناية تتابع المقاومة عبر الأجيال 
وتجدر الإشارة هنا إلى أن تسليم الراية من جيل إلى جيل يوضح تفاوت مستويات المقاومة وتطورها. "فالمواجهة هنا متفاوتة في مستواها. "فالأول يعلن رفضه لعطية الإله هباو للخير الذي يأتي من عنده، و يبقى الأمر كذلك حتى يرسل إليه هبا عاصفة هوجاء فتقتله، فهذا البطل هو بطل ثائر يعبر عن ثورته بالتمرد، و الرفض المطلق، لكن حالة المجابهة عنده جاءت أقل منها

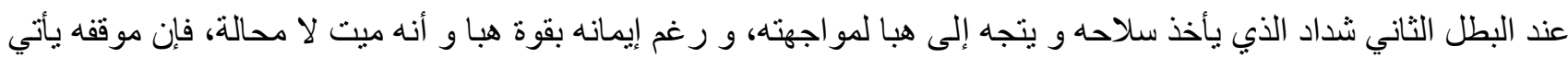
نتيجة لقناعاته بأن الموت في ساحة المعركة يبعث الفخر و الاعتز از أكثر من البقاء في صمت و خنوع و الموت موتا مجانيا، بينما الحفيد مرثذ فلم يختر طريقة بعد، و على الأغلب أنه سيبدأ بوعي أفضل من سابقيه، إذ سيختار الخيار النضالي الثوري"(عيسى ونقرش، 2013، ص: صن: 557). هنا يود كنفاني احالتنا إلى نقطة مرجعية هامة وهي أن الأمل في الانتصار لن يتحقق إلا بالنضال الفكري و الثقافي وليس المادي و الجسدي فقط، كيفما فعل عاد أو شداد قديما، حيث اكتفا بالرفض أو المجابهة الحربية فقط. فالحرب القادمة ليست حرب عسكرية بقدر أنها حرب وعي، يحتاج فيها المو اطن الفلسطيني التسلح بالعلم والفكر، وليس القنابل و الصواريخ فقط، إن وجدت في ظل الظروف الاقتصادية الطاحنة. ومن ثم فإن الجيل الجديد بقيادة مرثد عليه التعامل مع القضية الفلسطينية بشكل أكثر ذكاء وحنكة متسلحين بالو عي. فحين يطلب الكاهن من مرثذ أن يلقي خطابا في مر اسم تتويجه كملك جديد ويتوجب عليه حينها تعظيم وتمجيد هبا، يو افق مرثد على الفور، رغم نيته المسبقة بإعلان التحدي عليه ومقاومته مثل أجداده، ولكنه أراد أن بكتسب القوة كي يستطيع فعل ذلك. و إن كان هذا يعطي بصيصا من الأمل بأن المقاومة الفلسطينية مستمرة تتوارثها أجيال تزداد عنادا وذكاءً ضد المحتل الصهيوني الذي قد يمثل هنا الآلهة الني تحاول قمع حرية الفلسطينيين. 4- تصوير الجحيم في الباب والجلسة سرية

تماما كما صور سارتر الحياة الأخرى في مسرحية الجلسة سرية على هيئة غرفة مغلقة بها اشخاصا يتحكمون في مصير الآخرين، نأثر كنفاني في مسرحيته الباب بهذه الفكرة، حيث صور شداد بعد موته بأنه انتقل إلى غرفة مغلقة بها رجلان يشتغلان بأعمال الخياطة، وقد كلفهما هبا بخياطة ثوب من أجل الفوز بفتاة تتحكم بمصير هما وتجلس في حجرة مجاورة:

"الرجل: إن وجودك هو شيء مستمر ولا نهاية له، وبالتالي فأتت المسؤول الأوحد عنه ..

شداد: كيف؟ هل فقدت عقلك أيها الرجل، فقدت عقلك! أريد أن أعرف هل هو الذي أثر عليك إلى هذا الحد؟ أعنى هبا،

هل هو الذي أقنعك بكل هذا الغباء؟ أنت تعيش هنا كالبقرة، تعيش كحيوان لا أكثر .. تعيش كما لو أنكا ..

الرجل الثاني: (يقاطعه وينقر على كتف زميله، الآخر يهز رأسه ويبتسم) هل سمعته؟ أنه يقول أنت تعيش! ما زال يفكر برأس من تراب .. (ينظر إليه بشفقة مفتعلة) هل نسيت أيها القتى أنتا أموات؟ شداد: (برعب) صحيح، نحن أموات!"(كنفاني، 2014، ص:54-55). 
ولعل جملة الرجل الأول إن وجودك هو شيء مستمر ولا نهاية له، وبالتالي فأتت المسؤول الأوحد عنه، ترجعنا إلى أساس فلسفة سارتر (الوجود يسبق الماهية) فنرى تأثر كنفاني بفلسفة سارتر الوجودية واضحة، وهنا يكثف شداد للرجل عن حقيقة الوجود الإنساني وهو أن الإنسان لبس مخير ا في أفعاله، و إنما هو يُعامل مثل الحيوان، و لا يملك الإرادة الحرة كما كان يظن الرجل. وهو ما يؤكده تحكم الآخرون في الغرفة المجاورة بشداد و الرجلان، حيث كل شخص يتحكم في الآخر ويقمع حريته، لتتطبق مقولة سارثر (الجحيم هو الآخرون)، وهو موقف مشابه للصراع الثناثي بين إستيل وجارسان و إينيز مع بعضهما البعض في مسرحية الجلسة سرية:

\section{"شداد: (غاضبًا) هراء! (يشير إلى الرجلين المنهمكين في عملهما) انظر ماذا فعلت بهذين المسكينين، وأنظر بماذا حكمت عليهما .. ألم تكن تلك هي كلمتك التهائية؟ ألم يكن حكمك؟ هبا: ورغم ذلك، فأن لا أحكم قط، أنا أقترح فقط .. شداد: من الأي يحكم إذن؟ هبا: (يدور بأصبعه بهدوء مشيرًا إلى الجدران) أولئك الموجودون في الغرف الأخرى، إنهم يحكمون عليك أو للك .. شداد: كيف يحكمون علي دون أن يعرفوني؟ هبا: إنهم يحكمون عليك لأنهم لا يعرفونك . . شداد: هل من الضروري أن يحدث هذا لي؟ هبا: كلا! إنه يحدث لهم .. الحكم على الآخرين قضية لا تهم المحكوم عليهم تهم الحاكم .." (كنفاني، 2014، ص:62).}

لنعود إلى فلسفة الجحيم هو الآخرون، وتصور الحياة الأخرى بأنها مكان مغلق ودائرة مكتملة، لا الرجلان يكملا الثوب، و لا مفر من حكم الآخرون. ليقترح هبا على شداد بمهمة لا تتنهي وهي؛ أن يضرب كرة مطاط إلى الحائط وعندما ترند يلتقطها ويقذفها مرة أخرى و هكذا. وذلك تماما مثلما يحدث في آخر مشهد من جلسة سرية لسارتر، حيث تصل الثخصيات في نهاية الأحداث إلى محاولة قتل بعضها البعض، فتسعى إستيل إلى قتل إينيز حتى تترك لها المجال حرا لإقامة علاقة مع جارسان، ولكنها تتفاجأ أن إينيز مينة بالفعل وهو ما يصدمه جميعا في نهاية المسرحية أن الجحيم الخاص بالآخرون لا مفر منه، و إنه سييقى كل منهم فيه ما لا نهاية، كما سيبقى شداد في جحيمه مع الرجال الآخرين إلى الأبد. وهنا يشترك الكاتبين في فكرة مفادها، أن الإنسان لا يملك الحرية في أفعاله، فهو لا يملك قدرة الخلاص سواء بالهرب أو حتى بالانتحار، فجميع البشر مجبرون على العيش معا دون حرية و إلى ما لا نهاية. بثثير أيضا كنفاني فكرة أن الإنسان مجبر ا على آلهته، وليس أفعاله ونهايته فقط، وذلك من خلال مقتطف هام في النص، يؤكد فكرة الاجبار: 
"ثداد: لقد علمتموني طاعة هبا منذ نعومة أظافري .. وكنتم تقولون لي لو أطعته أدخلني الجنة، الجنة كاتت كل شيء في هبا .. لذلك وضعت في ذهني أن أبنى جنتي فأتخلص من هبا..

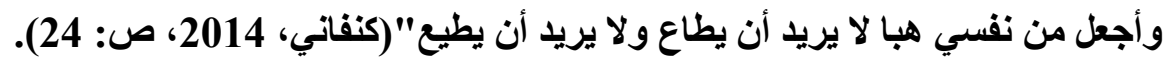
يتبلور فكر كنفاني في محاولة الثورة على جميع المعتقدات الراسخة التي حولت الإنسان إلى مجرد دمية يتلاعب بها بعض المتسترين في ثوب الآلهة ويتحدثون باسمهم، وهو الأمر الذي يعد اسقاطا سياسيا أيضا على دول الاحتلال التي تتحكم في مصائر الدول و الثعوب المستضعفة، داعية الجميع إلى طاعتها والامنتال لأو امرها، وكأنها خليفة اله على الأرض. وهنا لا يبقى لكنفاني إلا محاولة الثورة والتمرد على جميع هذه الأفكار ، حنى لو كانت النهاية محتومة ووشيكة:

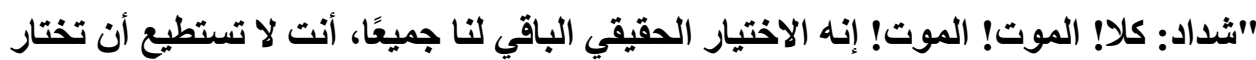
العياة لأنها معطاه للك أصلاً .. والمعطى لا اختيار فيه .. اختيار الموت هو الاختيار الحقيقي، أن تختاره في الوقت المناسب قبل أن يفرض عليك في الوقت غير المناسب قبل أن ثُدفع إليه بسبب من الأسباب التي لا تستطيع أن تختار ها كالمرض أو الهزيمة

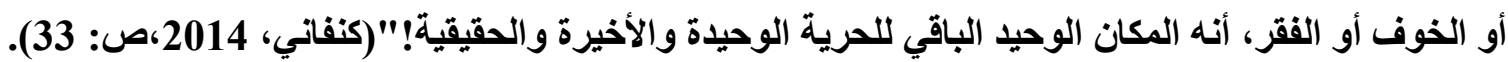
يوضح كنفاني في المقتطف السابق أن الإنسان يجب عليه التمرد على كل الأشياء التي تتحكم في مصيره سواء قوى عليا مثل هبا أو قوى سياسية مثل المحتل، ومن ثم يظهر التمرد هنا بشكل فلسفي مثلما يظهر في مسرحية كاليجو لا لالبير كامو، حيث يتوق كاليجو لا لملامسة القمر، لإثبات قدرته على التمرد والوصول إلى المستحيل، حتى لو كان الموت محتوما. فالأمر يعد انتصار اللفكر الثوري فلسفيا وليس و اقعيا، وهو ما كان يحلم به كنفاني في استمر ار الثورة ضد الاحتلال. وهو ما يوضحه مرثد من خلال كلامه عن ثورة أبيه على هبا، وأن مجرد تحديه لهبا هو انتصار اللإرادة الحرة، حتى لو كان الموت هو النهاية المتوقعة:

"مرثذ: من الأفضل لجسد والدي أن يبقى في الصحراء حتى يذوب بلا أن يحمل إلى مذبح هبا فيحرق تكفيرًا عن خطاياه .. لا أحب لوا الدي أن يخسر المعركة ميتًا بعد أن ربحها حيًا

الأم: (باكية ) أو تعتقد أنها ربحها ؟ مرثذ: لقد نفذ إرادته، قاتل هبا ودمر جنته. الأم: ولكنه مات .. ألا يعنى هذا شيئًا؟

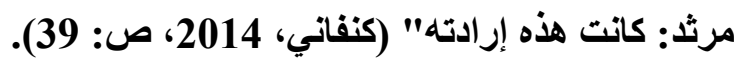
يدعو هنا كنفاني إلى أهمية التمرد والاختيار في مسرحياته مثلما كان يقول سارنر في سن الرشد: " أن الإنسان بقف بمفرده وسط سكون موحش مفزع، بلا عون و لا عذر، فقد حكم عليه أن يقرر مصبره دون رجعة ممكنة، كما حكم عليه أن يكون حرا إلى الأبد "(فام،1964: 160). فالثورة تبدأ عند كنفاني بهدم كل المعتقدات التي تقوض حرية الإنسان وتجعله حبيسا لها وتنتهي بالثورة على جميع أنواع القعع الأخرى المتمثلة في الاحتلال والخونة والمتو اطئين في الواقع السياسي وليس في عالم الفلسفة فقط. ولعل هذا الفكر مستمد من الفلسفة الماركسية، إذ أن جميع الأفكار الماركسية كانت تحمل فلسفات واقعية حسية تبدأ من الو اقع وتنتهي إليه فكل ما هو في الوجود من أفكار، وحياة اجتماعية، ما هي إلا انعكاسات للمادة الني ترتد إليها، 
الهجلة الدولية لنشر البحوث والدراسات

International Journal of Research and Studies Publishing
المجلد الثالث - الإصدار السادس والعشرون تأريخ الإصدار: 20 ديسمبر 2021م

ويبدأ منها الجدل. ومن ثم يدعو كنفاني في فلسفته الوجودية الشعب الفلسطيني أن يهدم الجوانب المكبّلة بالعادات والتقاليد الاجتماعية، وأن يخرج من أسطورته، ومن معجز اته الإلهية نحو تفكير أكثر و اقعية وعلمية. "إنّه الولوج إلى عالم المحسوسات و التفكير النقدي للتجربة. هي دعوة للخروج عمّا هو سائد في حياتتا اليومية الاجتماعية نحو مساحة أوسع من الحرية"(أبو ناصر، 2021).

و هو ما يوضحه شداد من خلال متقطف هام يوضح رمزية الباب وأنه السبيل الوحيد إلى الخروج للحرية والانعتاق من جميع أنواع الظلم و الاستبداد و القو انين الجائرة:

"ينهض، يهز شداد بعنف، وهو يشير إلى الباب، أترى هذا الباب، أنظر إليه جيدا! لقد تآتلت أظافري، و أنا أخثمه كالقط المجنون، لقد ذابت عظامي من فرط ما انهمرت فوقه...لقد حطمت جمجمتي كي أثثى ثغرة تتسع لطيران كلمة حقيقية واحدة...ثم ماذا؟ كنت أتهاوى كالقطن، هنا، نعم! (كنفاني، 2014، ص: 73). يدعو كنفاني هنا إلى الثورة على هبا حتى آخر نقطة دماء. حيث يقدم شداد نفسه للموت في شموخ وتمرد، ويتحول إلى رمز يحتذي به الأجيال القادمة ليو اصلو ا مسيرتهم ضد المحتل، وذللك لتحقيق كينونتهم ووجودهم في عالم لا جدوى له، يعاني فيه

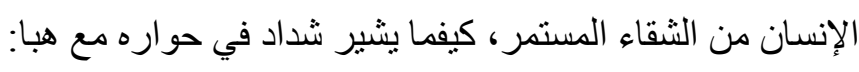
"شداد: العالم الذي وهبتنا إياه مقابل وعد مجهول كان عالما قميئا سخيفا.. عالما لا جدوى منه ولا غاية، لأن المرء يعيش فيه يتعذب ويذوب. لماذا؟ لأنه على موعد مع كلمة اسمها الجنة.. وما هو الثمن؟ أن يموت مخلفا كل شيء على حين فجأة!!"(كنفاني، 2014، ص: صبك: 64). يكتشف كنفاني بعدها فلسفته الخاصة في الحياة والآلهة وجميع المسلمات، حيث يضع شداد في موقف كاليجولا عندما تموت عشيقته ويتنقن أن الإنسان يموت و هو محروم من السعادة، يلهث داخل حلقة مفرغة من الثقاء مثل سيزيف، وهو ما يختم به هبا المسرحية موجها تحديه إلى شداد بأنه لن يتمكن من عبور الباب، فلا مفر من العذاب مثل حجرة جلسة سرية لسارنر : No Exit " هبا: هذه مملكتي! هذا الباب فقط: مملكة صغيرة ولكنها منيعة، العرش المجهول هو سر منعتها، والصولجان غير المرئي هو حارسها الأبدي" (كنفاني، 2014، ص:76).

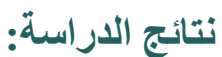

أهم نتائج البحث كثفت عن وجود تيار الوجودية في مسارحنا العربية، من خلال أعمال الكاتب الفلسطيني غسان كنفاني الذي لم يكتف بمضامين الفلسفة الوجودية الميتافيزيقية و الفلسفية فقط، بل قام بتطويع الفلسفات لخدمة قضايا وطنه في السياقات الزمنية و المكانية لوطنه العربي، وذللك من أجل فضح أساليب قمع حرية الثعب الفلسطيني واغتصاب أرضه على يد الكيان الصهيوني وبعض الخونة. ومن ثم نستطيع القول أن كنفاني أعاد صياغة المذهب الوجودي في مسرحه داخل إطار سياسي فلسفي يتناسب مع هموم وقضايا فلسطين، بصور وبأنتكال مختلفة منها الفانتازيا؛ مثل مسرحية القبعة والنبي، ومنها الأساطير القديمة مثل مسرحية الباب التي تعد صياغة مسرحية جديدة للفلفة الوجودية، تحمل رؤى سياسية وو اقعية من أجل الثورة و التمرد، يغلفها التناص مع أفكار ونصوص بعض الكتاب الوجودين مثل سارنر وكامو. 
قائمة المصادر والمراجع

أولا: المصادر العربية والمترجمة

ـ سارتر ، جان بول. ( 2016). مسرحية الذباب أو الندم، نرجمة وتقديم محمد القصاص، القاهرة: المركز القومي للترجمة. ـ سارنر، جان بول. (1958). مسرحية جلسة سرية ، نرجمة مجاهد عبد المنعم مجاهد. القاهرة: دار الثناء للنشر. ـ كامو ، البير. (1997). مسرحية كاليجولا ، نرجمة يوسف الجماني. دمشق: حور ان للنشر. ـ كنفانى، غسان. (2014 ). مسرحية الباب ، قبرص: دار منشور ات الرمال. ـ كنفانى، غسان. (2015). مسرحية القبعة و النبي، قبرص : دار منشور ات الرمال. ثانيا: المراجع العربية والمترجمة

ـ أبو ناصر، منولي. (2021). في مسرح كنفاني. مركز الجرمق للاراسات (موقع إلكتروني). تم الاستخر اج من: https://2u.pw/1HDsa

- بدوي، عبد الرحمن. ( 1980 ). دراسات في الفلسفة الوجودية، بيروت: المؤسسة العربية للار اسات و النشر. ـ الحمامصي، محمد. (2016). تأملات في المسألة اليهودية. جان بول سارتر. جريدة البيان. نم الاستخراج من: https://www.albayan.ae/books/from-arab-library/2016-03-25-1.2602650 ـ فام، لطفي. (1964). المسرح الفرنسى المعاصر، الدار القومية للطباعة و النشر.

ـالقصاص، محمد. (2016 ). جان بول سارنر و الحركة الفكرية السارترية (مقدمة/لطبعة الأولى لمسرحية الذباب )، القاهرة:

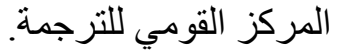
ـ كرستيفا، جوليا. (1991). علم النص، ترجمة فريد الز اهي، (مر اجعة عبد الجليل ناظم). الدار البيضاء، دار توبقال للنشر. ـ منصور، نائلة. (2020). تاريخ الوجودية في المشرق العربي. موقع الجههورية الإكترونسي. نم الاستخراج من: https://cutt.us/3XBDT - ميزر ائي، حسين. (2011). التناص الأدبي، ومفهومه في النقد العربي الحديث. موقع ديوان العرب. ثم الاستخر اج من: https://2u.pw/R2j2R - يحيى عيسى، و عمر نقرش. (2013). توظيف التراث في النص المسرحي الفلسطيني، مجلة جامعة النجاح للأبحاث (العلوم الإنسانية)، المجلد 27(3). 
الهجلة الدولية لنشر البحوث والدراسات

International Journal of Research and Studies Publishing

ISSN: 2709-7064
المجلد الثالث - الإصدار السادس والعشرون تأريخ الإصدار: 20 ديسمبر 2021م

\section{ثالثا: المراجع الأجنبية}

- Aldegheishem.H. (2015). Existentialism Staged: A Comparative Study between Beckett's

"Waiting for Godot" and Kanafani's "The Hat and the Prophet". Arab World English Journal

.Vol (6). No (2). Pp: 295 - 301. Retrieved from:

https://papers.ssrn.com/sol3/papers.cfm?abstract_id=2834398

- Clute, J., \& Grant, J. (Eds.). (1999). the encyclopedia of fantasy. Orbit.

- D i - Capua.Y. (2018). No exit: Arab existentialism, Jean-Paul Sartre, and

Decolonization. The University of Chicago Press. Chicago.

- Manlove.C.N. (2014). Fantasy versus Science Fiction. SF-TH Inc.

- Sartre, J. P. (2007). Existentialism is a Humanism. Yale University Press.

Doi: doi.org/10.52133/ijrsp.v3.26.1 